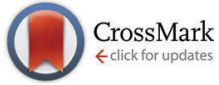

Cite this: Phys. Chem. Chem. Phys., 2015, 17, 25837

Received 18th March 2015, Accepted 20th April 2015

DOI: $10.1039 / c 5 c p 01573 a$

www.rsc.org/pccp

\title{
Gas-phase structure and reactivity of the keto tautomer of the deoxyguanosine radical cation $\dagger$
}

\author{
Linda Feketeová, ${ }^{\text {abcd }}$ Bun Chan, ${ }^{\text {tbe }}$ George N. Khairallah, ${ }^{\text {ab }}$ Vincent Steinmetz, ${ }^{\dagger}$ \\ Philippe Maître, ${ }^{f}$ Leo Radom ${ }^{\text {be }}$ and Richard A. J. O'Hair*ab
}

\begin{abstract}
Guanine radical cations are formed upon oxidation of DNA. Deoxyguanosine $(\mathrm{dG})$ is used as a model, and the gas-phase infrared (IR) spectroscopic signature and gas-phase unimolecular and bimolecular chemistry of its radical cation, $\mathrm{dG}^{\bullet+}$, A, which is formed via direct electrospray ionisation (ESI/MS) of a methanolic solution of $\mathrm{Cu}\left(\mathrm{NO}_{3}\right)_{2}$ and $d G$, are examined. Quantum chemistry calculations have been carried out on 28 isomers and comparisons between their calculated IR spectra and the experimentallymeasured spectra suggest that $\mathbf{A}$ exists as the ground-state keto tautomer. Collision-induced dissociation (CID) of $\mathbf{A}$ proceeds via cleavage of the glycosidic bond, while its ion-molecule reactions with amine bases occur via a number of pathways including hydrogen-atom abstraction, proton transfer and adduct formation. A hidden channel, involving isomerisation of the radical cation via adduct formation, is revealed through the use of two stages of CID, with the final stage of CID showing the loss of $\mathrm{CH}_{2} \mathrm{O}$ as a major fragmentation pathway from the reformed radical cation, $\mathrm{dG}^{\bullet+}$. Quantum chemistry calculations on the unimolecular and bimolecular reactivity are also consistent with $\mathbf{A}$ being present as a ground-state keto tautomer.
\end{abstract}

\section{Introduction}

Reports on the carcinogenic effects of ionising radiation date back to as early as 1902, and Marie Curie and her daughter Irene are believed to have succumbed to complications from radiation-induced leukemia. ${ }^{1}$ Early research on the effects of ionising radiation on $\mathrm{DNA}^{2}$ predated Watson and Crick's revelation of its structure, ${ }^{3}$ which provided an important molecular foundation for all subsequent research. ${ }^{4}$ It is now widely

\footnotetext{
${ }^{a}$ School of Chemistry and Bio21 Institute of Molecular Science and Biotechnology, The University of Melbourne, 30 Flemington Road, Parkville, VIC 3010, Australia. E-mail: gkhai@unimelb.edu.au, rohair@unimelb.edu.au; Fax: +61 3 9347-5180; Tel: $+6138344-2452$

${ }^{b}$ ARC Centre of Excellence for Free Radical Chemistry and Biotechnology, Australia

${ }^{c}$ Université de Lyon, 69003 Lyon, France

${ }^{d}$ CNRS/IN2P3, UMR5822, Institut de Physique Nucléaire de Lyon, 69622 Villeurbanne, France. E-mail: l.feketeova@ipnl.in2p3.fr

${ }^{e}$ School of Chemistry, University of Sydney, NSW 2006, Australia. E-mail: bun.chan@sydney.edu.au, radom@chem.usyd.edu.au; Fax: +61 2 9351-3329; Tel: +61 2 9351-5361

${ }^{f}$ Laboratoire de Chimie Physique, Université Paris Sud, 15, Avenue Jean Perrin, Orsay Cedex, 91405, France. E-mail: philippe.maitre@u-psud.fr;

Fax: +33 (0) 16915 6188; Tel: + 33 (o) 169153250

$\dagger$ Electronic supplementary information (ESI) available: Calculated structures and relative energies of $\mathrm{dG}^{\circ}$ isomers (Fig. S1 and S2), calculated IR spectra of $\mathrm{dG}^{\bullet+}$ isomers (Fig. S3), assignment of the experimental IR spectrum, MS/MS CID spectra of $\mathrm{dG}^{\bullet+}$ (Table S1), calculated thermochemical properties of $\mathrm{dG}^{{ }^{+}}$isomers (Fig. S4), and transition structure for keto-enol tautomerisation in $\mathrm{dG}^{\bullet+}$ (Fig. S5). See DOI: 10.1039/c5cp01573a
}

recognised that oxidative damage to DNA, through nucleobase modifications and the formation of strand breaks, can cause mutagenesis, cancer and is involved in aging. ${ }^{5}$

Extensive research focusing on a molecular understanding of the effects of ionising radiation on DNA and its consequences ${ }^{6}$ has revealed that the holes produced during the initial ionising event in DNA transfer mostly to the guanine (G) sites, which have the lowest ionisation energy (IE) of the four DNA bases. ${ }^{7}$ Thus, the electron-loss centre generated in duplex DNA ultimately ends up at guanine sites via hole migration through the DNA duplex. On loss of one electron, the resultant DNA base radical cation has a greatly increased acidity. For example, work on DNA models has demonstrated that the acidity of deoxyguanosine is enhanced in aqueous solution by around 5.6 orders of magnitude (5.6 $\mathrm{pK}_{\mathrm{a}}$ units) upon oxidation. ${ }^{7}$ Thus, proton-coupled electron and hole transfer becomes an important feature in the radiation damage process. ${ }^{6}$ One proposed pathway to strand breakage in DNA proceeds via species resulting from deprotonation of the guanine radical cation, which trigger specific hydrogen-atom abstraction reactions from the sugar moiety, ${ }^{8}$ thereby causing the heterolytic elimination of the phosphate-ester bond. ${ }^{9}$

Infrared (IR) spectroscopy integrated to tandem mass spectrometry has emerged as an important tool to characterise the structure of mass-selected and trapped molecular ions. ${ }^{10}$ The highly intense and tuneable IR beam delivered by Free Electron Lasers (FEL) ${ }^{11,12}$ is particularly well suited since it provides access 
to the so-called IR fingerprint region. As a result, isobaric ions bearing distinct functional groups can be clearly distinguished. Thus, the tautomers of protonated pyrimidic bases (thymine, cytosine, and uracil) have been characterised. ${ }^{13}$ It turns out that the CO stretching region around $1800 \mathrm{~cm}^{-1}$ is the most diagnostically useful part of the IR spectrum, since it is characteristic of the keto form. Although the spectral assignment in the 1500$1800 \mathrm{~cm}^{-1}$ region is more challenging, it also appears to be very informative for the structural assignment of tautomers.

We have recently shown that mass-spectrometry-based gasphase studies that combine the use of IR spectroscopy, ionmolecule reactions and computational chemistry provide a powerful way of relating the structure of radical cations of relevance to biological damage to their fundamental chemistry. ${ }^{14,15}$ For example, we have used IR spectroscopy to show that the radical cation of 9-methylguanine (9MG) has the same ground-state keto tautomer found in DNA, and discovered via the use of ion-molecule reactions that its $\mathrm{N}-\mathrm{H}$ acidity is enhanced by $\sim 470 \mathrm{~kJ} \mathrm{~mol}^{-1}$ in the gas phase. ${ }^{15}$ As noted in our previous paper, ${ }^{15}$ a key motivation for our studies is that Steenken has emphasised that the local environment experienced by nucleobases within DNA is different to model systems in bulk water, and suggested that gas-phase acidity data may be more appropriate to characterise the equilibrium position of the proton in oxidised GC base pairs. ${ }^{6 c, 7 a}$

Given that sugar radicals have been implicated as products arising from ionisation at guanine sites, we examine here the gas-phase IR spectrum, and the bimolecular and unimolecular chemistry of the deoxyguanosine radical cation, $\mathrm{dG}^{\bullet+}$. In previous work, we showed that electrospray ionisation (ESI) of a solution of $\mathrm{dG}$ and $\mathrm{Cu}\left(\mathrm{NO}_{3}\right)_{2}$, coupled with multistage collisioninduced dissociation (CID) in an ion-trap mass spectrometer, resulted in isomeric $\mathrm{dG}^{\bullet+}$ species $\mathbf{A}$ and $\mathbf{B}$, which could be

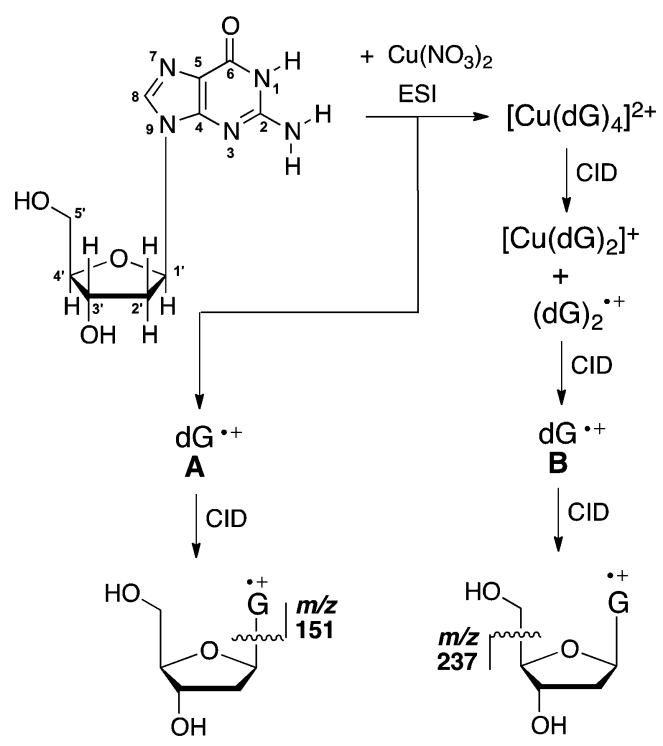

Scheme 1 Structure and atom numbering of the anti form of the neutral keto isomer of deoxyguanosine (dG), together with the experimental procedure for the formation of isomeric $\mathrm{dG}^{\bullet+}$ species (A and $\mathbf{B}$ ) via $\mathrm{ESI} / \mathrm{MS}^{n}$, and their resultant fragmentation channels under conditions of collisioninduced dissociation (CID). distinguished by their different fragmentation behaviour under CID (Scheme 1). ${ }^{16 b}$ Thus, the major fragment ion formed from A arises from cleavage of the glycosidic bond. In contrast, formaldehyde loss is the major fragmentation channel for $\mathbf{B}$. We speculated that the difference in the unimolecular chemistry was due to the nucleobase moiety G, existing in different tautomeric forms in $\mathbf{A}$ and $\mathbf{B} .^{16 b}$

Here we use gas-phase IR spectroscopy, ion-molecule reactions and quantum chemistry calculations to interrogate the structure and reactivity of species $\mathbf{A}$, which is formed via direct ESI/MS. Compared with the radical cation of $9 \mathrm{MG},{ }^{15}$ the presence of the sugar moiety greatly increases the number of isomers whose structures, energies and IR spectra need to be considered by quantum chemistry calculations. Apart from the keto and enol tautomers, there are the syn and anti conformational isomers associated with rotations around the C-N glycosidic bond. ${ }^{17}$ In addition, distonic ions can be formed via $\mathrm{H}$-atom transfer from the sugar to the nucleobase radical cation.

\section{Methods}

Reagents were used as supplied: $\mathrm{Cu}\left(\mathrm{NO}_{3}\right)_{2}$ (Ajax chemicals, 99\%) and deoxyguanosine (Sigma, 99\%). Complexes were prepared by mixing 2:1 mM solutions of the nucleoside: $\mathrm{Cu}\left(\mathrm{NO}_{3}\right)_{2}$, dissolved in $3: 1$ methanol : water, immediately before infusing the reaction mixture into the mass spectrometer.

\section{Infrared spectroscopy}

IR spectroscopy in the $1000-2000 \mathrm{~cm}^{-1}$ spectral range was carried out using the FEL of CLIO ${ }^{12}$ coupled to a hybrid FT-ICR tandem mass spectrometer. ${ }^{18}$ Hybrid stands for the fact that prior to the transfer to the ICR cell, electrosprayed ions can be mass-selected in a quadrupole and accumulated in a linear hexapole pressurised with $\operatorname{Ar}\left(\sim 10^{-3}\right.$ mbar $)$ allowing for CID and/or thermalisation of the ions. As described previously, $\mathrm{dG}^{\bullet+}$ species A can be observed directly by ESI. ${ }^{16}$ Following mass-selection, the isolated $\mathrm{dG}^{\bullet+}$ (species A) was irradiated with the FEL IR beam for 250 or $500 \mathrm{~ms}$. On the basis of previous results, ${ }^{18}$ it is important to emphasise that the mass-selected radical ions are subjected to multiple collisions with argon, thus ensuring an efficient thermalisation prior to the pulsed extraction towards the ICR cell.

Upon resonant vibrational excitation, dissociation of the $\mathrm{m} / \mathrm{z}$ 267 radical ions was monitored via the formation of the diagnostic $m / z 151$ fragment peak ions. The abundance of this photofragment and its corresponding precursor were recorded as a function of the IR wavelength in order to derive the IR action spectra, where the IR multiple-photon dissociation (IRMPD) efficiency is plotted against the photon energy, which was varied stepwise.

\section{Mass spectrometry}

All mass spectrometry experiments were carried out using a commercially available Finnigan-LTQ-FT (Thermo, Bremen, 
Germany) mass spectrometer equipped with ESI source ${ }^{19}$ described in detail elsewhere. ${ }^{20}$ The procedure used to generate $\mathrm{dG}^{\bullet+}$ species $\mathbf{A}$ was as described above. The sample was introduced into the mass spectrometer at $5.0 \mu \mathrm{L} \mathrm{min}{ }^{-1}$ via ESI. Typical ESI conditions used were: spray voltage, $3.3-5.0 \mathrm{kV}$; capillary temperature, $250{ }^{\circ} \mathrm{C}$; nitrogen sheath pressure, 8-40 (arbitrary units). The capillary voltage and the tube lens offset were tuned to maximise the desired peak. The injection time was set using the automatic gain control function. The LTQ-FT mass spectrometer consists of (i) a linear ion trap (LTQ); (ii) ion-transfer optics; and (iii) an FT-ICR mass analyser. For the tandem mass spectrometry (MS/MS) experiments, $\mathrm{dG}^{\bullet^{+}}$ species A produced via ESI was trapped in the LTQ and subjected to CID at an He bath gas pressure of $c a .2 \times 10^{-3}$ Torr. CID was carried out by mass selecting the desired ions with a $1.5-6 \mathrm{~m} / \mathrm{z}$ units window and subjecting them to the following typical conditions: normalised collision energy between $16 \%$ and $40 \%$, which determines the translational kinetic energy of the ions; activation $(Q), 0.25-0.35$, which assigns the radio-frequency (RF) amplitude used to fragment ions, and activation time of $30 \mathrm{~ms}$ that is the time set to excite the ions via CID. The high resolution of the FT-ICR mass spectrometer was used to confirm the charge states of the mass-selected precursor ions. For highresolution mass analysis, the ions were transferred via the ion optics transfer region $\left(2 \times 10^{-7}\right.$ Torr $)$ into an FT-ICR cell at a pressure below $1.5 \times 10^{-9}$ Torr.

\section{Ion-molecule reactions}

The mass spectrometry instrument described above has been modified to allow ion-molecule reactions (IMRs) to take place in the LTQ. ${ }^{21} \mathrm{dG}^{\bullet+}$ species A was trapped in the LTQ and subjected to IMRs with the desired neutral reagents: diisopropylethylamine $\left(\mathrm{iPr}_{2} \mathrm{NEt}\right)$, triethylamine $\left(\mathrm{Et}_{3} \mathrm{~N}\right)$, and diisopropylamine $\left(\mathrm{iPr}_{2} \mathrm{NH}\right)$. IMRs between the mass selected $\mathrm{dG}^{\bullet^{+}}$ species $\mathbf{A}$ and the various bases were carried out with reaction times varying between 30 and $1000 \mathrm{~ms}$. Branching ratios of the products were calculated by integrating the intensities under the appropriate peaks.

\section{Computational methods}

Standard density functional theory calculations were carried out with Gaussian 09. ${ }^{22}$ Geometries were optimised at the B3-LYP/6-31+G(d,p) level. Improved single-point energies were obtained using the M06-2X/6-311+G(3df,2p) protocol. ${ }^{23}$ Zeropoint vibrational energies and thermal corrections for enthalpies at $298 \mathrm{~K}$ were obtained using scaled B3-LYP harmonic vibrational frequencies. ${ }^{24}$ Unless otherwise noted, energies in the text refer to free energies at $298 \mathrm{~K}$. The vibrational frequencies (B3-LYP) used for the simulated IR spectra were scaled according to literature recommendations. ${ }^{25}$ A scaling factor of 0.98 was applied to the calculated B3-LYP/6-31+G(d,p) harmonic frequencies in the $1000-2000 \mathrm{~cm}^{-1}$ region. Each calculated band was convoluted assuming a Gaussian shape with full width at half maximum of $20 \mathrm{~cm}^{-1}$.

\section{Results and discussion}

\section{IR spectroscopy of $\mathrm{dG}^{\bullet+}$ species A directly formed via ESI/MS on copper(II) solutions}

The gas-phase deoxyguanosine radical cations, $\mathrm{dG}^{\bullet+} \mathbf{A}$, formed via electrospray ionisation of a methanolic solution of a mixture of copper nitrate and $\mathrm{dG},{ }^{16}$ were mass selected and stored in the cell of a Fourier transform ion cyclotron resonance mass spectrometer, where they were subjected to infrared radiation. The resulting IR multiple-photon dissociation (IRMPD) spectrum shown in Fig. 1a was obtained. Table S1 (ESI $\dagger$ ) lists the experimental band positions.

The IR spectrum is dominated by an unresolved feature with two maxima at $\sim 1595$ and $\sim 1650 \mathrm{~cm}^{-1}$. The band observed at $\sim 1750 \mathrm{~cm}^{-1}$ when $\mathrm{dG}^{\bullet+}$ ions are formed in the source region is characteristic of a $\mathrm{C}=\mathrm{O}$ stretching mode. Two other intense bands are observed at $\sim 1110$ and $\sim 1372 \mathrm{~cm}^{-1}$. Finally, weaker features are observed at $\sim 1200, \sim 1275$, and $\sim 1511 \mathrm{~cm}^{-1}$.

The experimental IR spectrum of $\mathbf{A}$ is compared with the spectra calculated (at the B3-LYP/6-31+G(d,p) level) for a number of different tautomers lying within $50 \mathrm{~kJ} \mathrm{~mol}^{-1}$ in free energy (at the M06-2X/6-311+G(3df,2p) level) of the lowest-energy isomer 1a, together with some higher-energy tautomers such as one proposed in our previous study. ${ }^{16 b}$ A total of 28 tautomers of $\mathrm{dG}^{\bullet+}$ were examined theoretically in this way, and their structures and IR spectra are given in Fig. S1-S3 (ESI $\dagger$ ).

An examination of the calculated IR spectra (Fig. 1 and Fig. S3, ESI $\dagger$ ) shows that the IR spectrum is very sensitive to the nature of the tautomers. The experimental spectrum (Fig. 1a) nicely matches the spectrum calculated for the lowest-energy keto tautomer 1a (Fig. 1b). On this basis, band assignments are proposed in Table S1 (ESI $\dagger$ ). As mentioned

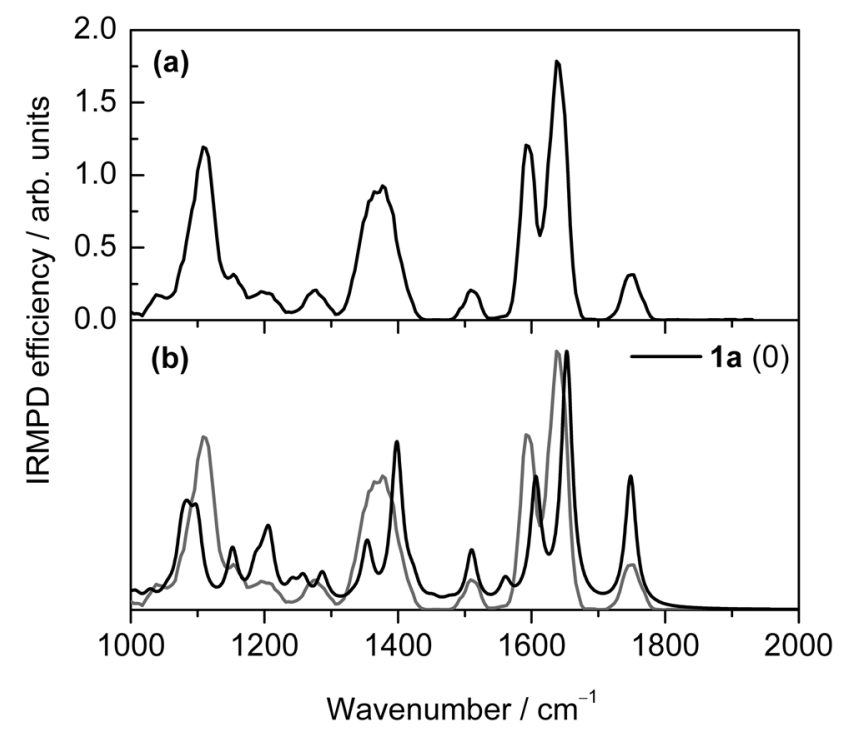

Fig. 1 Experimental and (scaled) theoretical (B3-LYP/6-31+G(d,p)) IR spectra of $\mathrm{dG}^{\bullet+}$ : (a) experimental spectrum of $\mathbf{A}$ with IRMPD efficiency, (b) theoretical spectrum for the lowest-energy keto isomer 1a. The experimental spectrum is included for comparison in gray in (b) and the scaling factor used is 0.98 . 
above, the band observed at $\sim 1750 \mathrm{~cm}^{-1}$ is a signature of a keto isomer, and the corresponding $\mathrm{C}=\mathrm{O}$ stretching mode is predicted at $1748 \mathrm{~cm}^{-1}$ for the lowest energy isomer 1a. A very good agreement between theory and experiment can also be found for the lower energy bands, which are assigned to the ring deformation (N3-C4 stretching) (1a: $1653 \mathrm{~cm}^{-1}$, expt: $1640 \mathrm{~cm}^{-1}$ ), $\mathrm{NH}_{2}$ scissoring (1a: $1606 \mathrm{~cm}^{-1}$, expt: $1595 \mathrm{~cm}^{-1}$ ), guanine six-membered-ring breathing (1a: $1510 \mathrm{~cm}^{-1}$, expt: $1511 \mathrm{~cm}^{-1}$ ), multiply-coupled $\mathrm{C}-\mathrm{H} / \mathrm{N}-\mathrm{H}$ bending (1a: 1353, 1355, and $1398 \mathrm{~cm}^{-1}$, expt: $1372 \mathrm{~cm}^{-1}$ ), and multiply-coupled guanine/sugar ring breathing (1a: 1076, 1084, 1089, 1099, and $1152 \mathrm{~cm}^{-1}$, expt: $1110 \mathrm{~cm}^{-1}$ ) modes. Thus we assign species A as the keto isomer 1a.

It is interesting to compare our results on the IR spectroscopic identification of the keto tautomer radical cation of dG with results for the parent neutral. ${ }^{26}$ Although the keto tautomer of $\mathrm{dG}$ is predicted to be more stable than the enol tautomer by $3.8 \mathrm{~kJ} \mathrm{~mol}^{-1}$, gas-phase IR spectroscopy of laser-desorbed dG only identified the enol tautomer, ${ }^{26 a, b}$ which has been ascribed to a short excited-state lifetime of the keto form in the twophoton ionization event required to generate the IR spectrum. ${ }^{26 c}$ In contrast, hydration of laser-desorbed dG by one or two water molecules, results in the keto form being observed in the gasphase IR spectrum. ${ }^{26 c}$ Thus the way the dG radical cation or neutral is transferred to the gas phase appears to play a key role as to which tautomer is formed. Although the exact mechanism by which $\mathrm{dG}^{\bullet+} \mathbf{A}$ is formed during the ESI process, which transfers species from solution to the gas phase, remains unknown, our assignment of this species as the keto form in the gas phase is consistent with the following known solutionphase chemistry of dG: (i) NMR studies have demonstrated that it exists largely as the keto tautomer in its neutral form; ${ }^{27}$ and (ii) upon binding of $\mathrm{Cu}^{2+}$, the keto tautomer is maintained. $\ddagger^{28}$

\section{Ion-molecule reactions of $\mathrm{dG}^{\bullet+} \mathrm{A}$}

The acidity of $\mathrm{dG}^{\bullet+} \mathbf{A}$ was estimated via IMRs with neutral reference bases $\mathrm{B}$ with known proton affinities. ${ }^{31}$ Five types of reactions were observed: proton transfer (PT, eqn (1)), electron transfer (ET, eqn (2)), hydrogen-atom abstraction (HAA, eqn (3)), adduct formation (AddF, eqn (4)), and complexation-induced fragmentation (CplxFr, eqn (5)).

\# A reviewer has asked about the mechanism for the formation of the deoxyguanosine radical cation in the gas phase. They can be formed via gas-phase fragmentation of mass-selected $\mathrm{Cu}$ (II) clusters whose stoichiometry is known, as shown for species $\mathbf{B}$ in Scheme 1. Species A is directly formed via ESI/MS, but the precise mechanism for its formation remains unclear. Under gentle source conditions such as those used here, Chen and Bohme have suggested that the related guanosine radical cations ${ }^{16 a}$ are formed via intra-complex transfer from a coordinated ligand (in our case deoxyguanosine) to the $\mathrm{Cu}^{2+}$ centre within $\mathrm{Cu}$ (II) clusters whose exact stoichiometry is unknown, followed by dissociation within the ESI source to form the free radical cation. We cannot rule out the possibility of an outer-sphere electron-transfer process from deoxyguanosine to a $\mathrm{Cu}(\mathrm{II})$ species during the ESI process. Both mechanisms are consistent with the coordinated ${ }^{28}$ or free ${ }^{27}$ keto tautomer being present in solution. On a final note, the ESI source behaves as an electrolytic flow cell ${ }^{29}$ and while radical cations of other substrates have been observed previously, ${ }^{30}$ the presence of $\mathrm{Cu}$ (II) is required to observe the formation of A via ESI/MS.

$$
\begin{aligned}
\mathrm{dG}^{{ }^{+}}+\mathrm{B} & \rightarrow(\mathrm{dG}-\mathrm{H})^{\bullet}+(\mathrm{B}+\mathrm{H})^{+} & & \text {PT } \\
& \rightarrow \mathrm{dG}+\mathrm{B}^{\bullet+} & & \text { ET } \\
& \rightarrow(\mathrm{dG}+\mathrm{H})^{+}+(\mathrm{B}-\mathrm{H})^{\bullet} & & \text { HAA } \\
& \rightarrow[\mathrm{dG}+\mathrm{B}]^{\bullet+} & & \text { AddF } \\
& \rightarrow[\mathrm{dG}+(\mathrm{B}-\mathrm{X})]^{+}+\mathrm{X}^{\bullet} & & \text { CplxFr }
\end{aligned}
$$

Table 1 provides a summary of the branching ratios (BRs) for these reactions, and a sample spectrum of the IMR of $\mathrm{dG}^{\bullet+}$ with $\mathrm{iPr}_{2} \mathrm{NEt}$ at $100 \mathrm{~ms}$ reaction time is shown in Fig. 2. We found that during the IMRs with the bases, the reactions did not go to completion and that the $\mathrm{dG}^{\bullet+}$ at $m / z 267$ was still observed even at very long reaction times (e.g., $10000 \mathrm{~ms}$ ). We attribute this observation to the complexation-induced isomerisation reaction of the $\mathrm{dG}^{\bullet+}$ radical cation, which produces a different isomer(s), which we call species $\mathbf{C}$. We base this conclusion on the CID spectrum of $\mathbf{C}$, which is formed in the following sequential $\mathrm{MS}^{n}$ reactions: (i) the IMR between $\mathrm{dG}^{\bullet+} \mathbf{A}$ and a base produces the adduct $[\mathrm{dG}+\mathrm{B}]^{++}\left(\mathrm{MS}^{2}\right)$; (ii) isolation of this adduct followed by CID results in loss of the base and generation of $\mathrm{dG}^{\bullet+} \mathbf{C}\left(\mathrm{MS}^{3}\right)$; (iii) isolation of $\mathrm{dG}^{\bullet+} \mathbf{C}$ allows its CID spectrum to be collected in an $\mathrm{MS}^{4}$ experiment.

As an example, the $\mathrm{MS}^{4}$ spectrum of $\mathrm{dG}^{\bullet+} \mathbf{C}$ is shown in Fig. S4a (ESI $\dagger$ ), where isomerisation has taken place through the reaction with $\mathrm{iPr}_{2} \mathrm{NEt}$, and the resultant new species $\mathbf{C}$ fragments via the major loss of formaldehyde. $\S$ In contrast, $\mathbf{C}$ is less reactive than $\mathbf{A}$ in IMRs with bases, and does not undergo reactions via eqn (1)-(3). Thus it appears that in IMRs of $\mathrm{dG}^{*+}, \mathbf{A}$ can not only react directly via eqn (1)-(3), but it can also undergo isomerisation. Such reactions have been observed in the gas phase before and Bohme has classed them as proton-transport-catalysed reactions. ${ }^{32}$ of particular relevance to the potential tautomers that might be formed in these reactions are previous observations of protontransport-catalysed reactions that isomerise the keto form of amide radical cations to their enol forms. ${ }^{33}$

Theoretical modelling of the ion-molecule reactions of the keto and enol tautomers is summarised in Fig. S5 (ESI $\dagger$ ). Note that the calculated M06-2X/6-311+G(3df,2p) proton affinities (PAs) of the bases are slightly underestimated by the theory (by 4-8 $\mathrm{kJ} \mathrm{mol}^{-1}$ ) while the IEs are slightly overestimated. Nevertheless, the experimental IMR results are consistent with the proton affinities calculated for the keto tautomer.

The PA for the $\left(9 \mathrm{MG}-\mathrm{H}_{\mathrm{N} 1}\right)^{\bullet}$ radical is $968.9 \mathrm{~kJ} \mathrm{~mol}^{-1}$ at the M06-2X/6-311+G(3df,2p) level. For the corresponding radical $\left(1 \mathrm{a}-\mathrm{H}_{\mathrm{N} 1}\right)^{\bullet}$ it is $993.5 \mathrm{~kJ} \mathrm{~mol}^{-1}$. This is consistent with the increase in PA on going from the nucleobase $\mathrm{G}\left(951.4 \mathrm{~kJ} \mathrm{~mol}^{-1}\right)$ to nucleoside dG $\left(980.7 \mathrm{~kJ} \mathrm{~mol}^{-1}\right){ }^{34}{ }^{34}$ Hence $\mathrm{iPr}_{2} \mathrm{NEt}$, which has the highest calculated PA of $990 \mathrm{~kJ} \mathrm{~mol}^{-1}$ (Fig. S5, ESI $\dagger$ ), appears to possess the highest branching ratio for eqn (1) (6\%, Table 1), whereas $\mathrm{Et}_{3} \mathrm{~N}$, with a calculated PA of $976 \mathrm{~kJ} \mathrm{~mol}^{-1}$ that is

$\S$ Due to their similar CID spectra, it is tempting to speculate that species $\mathbf{B}$ and $\mathbf{C}$ are composed of the same isomers. Ideally, we would have liked to have measured the IR spectrum of $\mathbf{C}$, but the instrument is not currently set up to allow gas-phase ion-molecule reactions. 
Table 1 Branching ratios (BR) for products of ion-molecule reactions of $\mathrm{dG}^{\bullet+}$ with reference bases (B)

\begin{tabular}{|c|c|c|c|c|c|c|}
\hline Base (B) & $\begin{array}{l}\text { Proton } \\
\text { affinity }^{a} \text { (B) }\end{array}$ & $\begin{array}{l}\text { BR PT } \\
(\text { eqn }(1))^{b}(\%)\end{array}$ & $\begin{array}{l}\text { BR ET } \\
(\text { eqn }(2))^{b}(\%)\end{array}$ & $\begin{array}{l}\text { BR HAA } \\
(\text { eqn }(3))^{b}(\%)\end{array}$ & $\begin{array}{l}\text { BR AddF } \\
(\text { eqn }(4))^{b}(\%)\end{array}$ & $\begin{array}{l}\text { BR CplxFr } \\
(\text { eqn }(5))^{b}(\%)\end{array}$ \\
\hline $\mathrm{iPr}_{2} \mathrm{NEt}$ & 994.3 & 6 & 18 & 2 & 60 & 13 \\
\hline $\mathrm{Et}_{3} \mathrm{~N}$ & 981.8 & $<1$ & 6 & 50 & 1 & 42 \\
\hline $\mathrm{iPr}_{2} \mathrm{NH}$ & 971.9 & $<1$ & 0 & 5 & 58 & 37 \\
\hline
\end{tabular}

${ }^{a}$ Values in $\mathrm{kJ} \mathrm{mol}^{-1}$ are taken from the NIST database (ref. 37). ${ }^{b}$ Branching ratios (BR) were determined as average values from measurements at several 100-1000 ms reaction times.

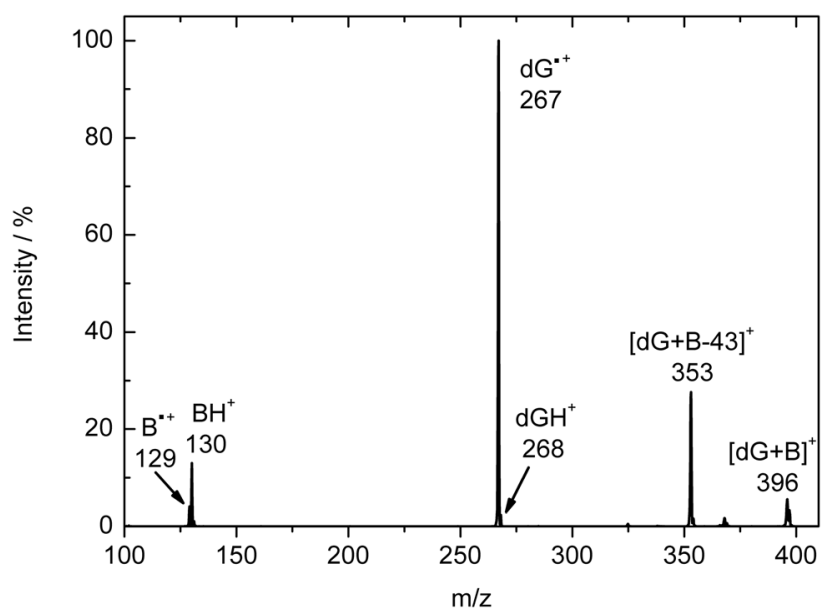

Fig. 2 Ion-molecule reaction spectrum of $\mathrm{dG}^{\bullet+}$ formed in the ESI source reacting with diisopropylethylamine $\left(\mathrm{iPr}_{2} \mathrm{NEt}\right)$ at $100 \mathrm{~ms}$ reaction time.

smaller than that of $(\mathbf{1 a}-\mathbf{H})^{\bullet}$, shows a branching ratio for eqn $(1)<1 \%$. The most acidic proton of $1 \mathrm{a}$ is the $\mathrm{C} 2 \mathrm{~N}-\mathrm{H}$ of the amino group, the proton that would be involved in a guaninecytosine pairing, consistent with the results observed for $9 \mathrm{MG}^{\bullet+} \cdot{ }^{15}$

The electron-transfer reaction (eqn (2)) depends on the IE of the bases versus the electron affinity (EA) of the $\mathrm{dG}^{\bullet+}$ radical cation. The calculated IEs (Fig. S5, ESI $\dagger$ ) for $\mathrm{iPr}_{2} \mathrm{NEt}, \mathrm{Et}_{3} \mathrm{~N}$ and $\mathrm{iPr}_{2} \mathrm{NH}$ are 705,744 and $756 \mathrm{~kJ} \mathrm{~mol}^{-1}$, respectively, whereas the EA of $1 \mathrm{a}$ is calculated to be $712 \mathrm{~kJ} \mathrm{~mol}^{-1}$. In this case also, theory is consistent with the experimental results, where the branching ratio for the $\mathrm{iPr}_{2} \mathrm{NEt}$ is the highest (18\%, Table 1) and that of $\mathrm{iPr}_{2} \mathrm{NH}$ is the lowest (0\%, Table 1). Our theoretical results are also consistent with the gas-phase IE of dG, which has been bracketed as $718 \mathrm{~kJ} \mathrm{~mol}^{-1}<\mathrm{IE} \mathrm{dG}<751 \mathrm{~kJ} \mathrm{~mol}^{-1}$ via the Cooks kinetic method, ${ }^{35}$ as well as with a literature value from DFT calculations of $730 \mathrm{~kJ} \mathrm{~mol}^{-1} \cdot{ }^{36}$

The energetics of the HAA pathway (eqn (3)) were also determined theoretically by calculating the bond dissociation energies (BDE) for the bases and comparing them with $\mathrm{H}$-atomabstraction energies for the $\mathrm{dG}^{\bullet+}$ radical cation (Fig. S5, ESI $\dagger$ ). The BDEs for $\mathrm{iPr}_{2} \mathrm{NEt}$ and $\mathrm{iPr}_{2} \mathrm{NH}$ are similar at 370 and $371 \mathrm{~kJ} \mathrm{~mol}^{-1}$, respectively, while the $\mathrm{BDE}$ for $\mathrm{Et}_{3} \mathrm{~N}$ is $398 \mathrm{~kJ} \mathrm{~mol}^{-1}$. According to the calculations, the $\mathrm{H}$ atom of the $\alpha \mathrm{C}$ can be readily abstracted only by the $\mathrm{N} 7$ of the $\mathrm{dG}^{\bullet+}$ radical cation in its keto form, i.e., 1a, where the energy for the abstraction is predicted to be $401 \mathrm{~kJ} \mathrm{~mol}^{-1}$ (Fig. S5, ESI $\dagger$ ). The energy for the abstraction of the $\mathrm{H}$ atom for the enol form is predicted to be
$<397 \mathrm{~kJ} \mathrm{~mol}^{-1}$, which is also consistent with the assignment of 1a to A. Interestingly, the branching ratio for the HAA pathway (eqn (3)) is $50 \%$ for $\mathrm{Et}_{3} \mathrm{~N}$, while for $\mathrm{iPr}_{2} \mathrm{NEt}$ and $\mathrm{iPr}_{2} \mathrm{NH}$ it is only $2 \%$ and $5 \%$, respectively. This can be attributed to the fact that formation of the adduct (eqn (4)) is in these cases more favourable, as shown by the high branching ratios for $\mathrm{iPr}_{2} \mathrm{NEt}$ and $\mathrm{iPr}_{2} \mathrm{NH}$ of $60 \%$ and $58 \%$, as opposed to the branching ratio for $\mathrm{Et}_{3} \mathrm{~N}$ of only $1 \%$.

Overall, the results of our computational investigations show proton transfers to neutral reagents that range from mildly endothermic $\left(+14 \mathrm{~kJ} \mathrm{~mol}^{-1}\right.$ for $\left.\mathrm{iPr}_{2} \mathrm{NH}\right)$ to mildly exothermic $\left(-12 \mathrm{~kJ} \mathrm{~mol}^{-1}\right.$ for $\left.\mathrm{iPr}_{2} \mathrm{NEt}\right)$. The trends in these calculated reaction energies are consistent with the observed experimental yields for proton transfer. In comparison, hydrogen abstraction from these bases by $\mathbf{1 a}$ is generally exothermic, with reaction energies ranging from $-3 \mathrm{~kJ} \mathrm{~mol}^{-1}$ for $\mathrm{Et}_{3} \mathrm{~N}$ to $-31 \mathrm{~kJ} \mathrm{~mol}^{-1}$ for $\mathrm{iPr}_{2} \mathrm{NEt}$. The relatively small energies for these proton-transfer (eqn (1)) or hydrogen-atom-abstraction (eqn (3)) reactions suggest that either class of reaction might be involved as an intermediate step for the observed isomerisation of $\mathbf{A}$ to $\mathbf{C}$. In any case, the calculated thermochemical quantities and the experimental branching ratios, as well as the very observation of $\mathbf{C}$, indicates a complex set of processes induced by IMRs.

Finally, it is worth considering the results of these gas-phase reactions within the context of the proposed biological chemistry of one-electron-oxidised guanine residues within DNA. It has been proposed that oxidised guanine residues have a significantly enhanced acidity, which allows them to undergo proton transfer to the adjacent cytosine residues. Our experimental results suggest that the $\mathrm{PA}$ for the $(\mathrm{dG}-\mathrm{H})^{\bullet}$ radical 1a (978$\left.996 \mathrm{~kJ} \mathrm{~mol}^{-1}\right)$ is close to that of $\operatorname{iPr}_{2} \mathrm{NEt}\left(994.3 \mathrm{~kJ} \mathrm{~mol}^{-1}\right)$. The gas-phase acidity of neutral dG has been recently determined to be $1409 \mathrm{~kJ} \mathrm{~mol}^{-1} \cdot{ }^{35,36}$ Thus in the gas phase, ionisation of dG enhances its acidity by $\sim 415 \mathrm{~kJ} \mathrm{~mol}^{-1}$, somewhat less than what we found for 9MG $\left(\sim 470 \mathrm{~kJ} \mathrm{~mol}^{-1}\right)$, but still a significant enhancement of acidity. Indeed, the enhanced acidity of $\mathrm{dG}^{\bullet+}$ is close to the PA of $\mathrm{dC}\left(988.4 \mathrm{~kJ} \mathrm{~mol}^{-1}\right)^{38}$ and this suggests that proton transfer within the ionised base pair may become viable. As noted in the introduction, a mechanism proposed for strand breaking in ionised DNA involves hydrogen-atom abstraction from the sugar moiety induced by deprotonation of the guanine radical cations. ${ }^{8}$ Our observation of a hydrogen-atom abstraction channel for $\mathrm{dG}^{\bullet+}$ suggests that ionised guanine sites within DNA may indeed be cable of inducing hydrogen-atom abstraction reactions. 

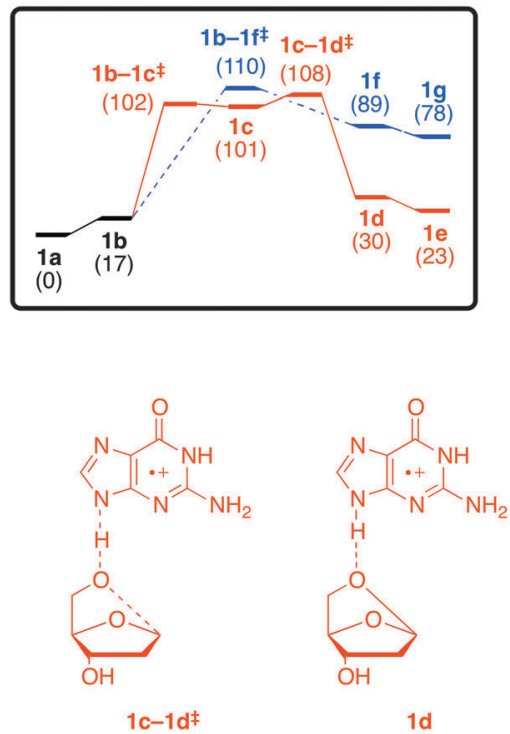

$1 d$

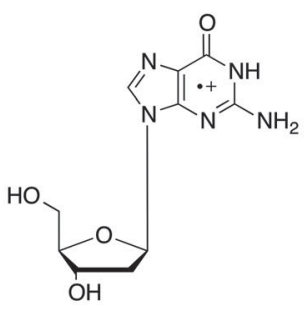

$1 a$

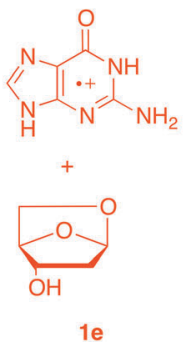

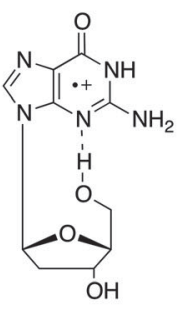

$1 b$

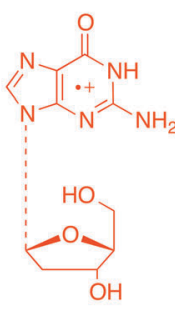

$1 b-1 c^{\ddagger}$

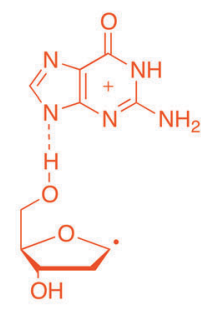

$1 c$

Fig. $3 \mathrm{M06}-2 \mathrm{X} / 6-311+\mathrm{G}(3 \mathrm{df}, 2 \mathrm{p})$ schematic free energy profile $\left(\mathrm{KJ} \mathrm{mol}^{-1}\right)$ associated with the fragmentation reactions of $1 \mathrm{a}$ via (a) loss of the cyclised sugar $\mathrm{C}_{5} \mathrm{H}_{8} \mathrm{O}_{3}$ (red), or (b) loss of $\mathrm{CH}_{2} \mathrm{O}$ (blue).

\section{A mechanism for the formation of $m / z 151$ in the unimolecular fragmentation of $\mathrm{dG}^{{ }^{+}}$species $\mathrm{A}$}

As noted in the introduction, the way in which the various $\mathrm{dG}^{\bullet+}$ species fragment depends on the way that they are generated (Scheme 1). The main dissociation channel in the low-energy CID spectrum of $\mathbf{A}$ is the cleavage of the $\mathrm{N}$-glycosidic bond to give the radical cation of the guanine base at $m / z 151,{ }^{18}$ (Fig. S4b, ESI $\dagger$ ) which contrasts with the series of fragment ions observed in the EI mass spectrum ${ }^{39}$ and upon REMPI. ${ }^{40}$ The IR spectroscopy and IMR results suggest that $\mathbf{A}$ exists as the keto tautomer (1a). Thus we have used DFT calculations to examine the energetics for loss of $\mathrm{C}_{5} \mathrm{H}_{8} \mathrm{O}_{3}$ (observed in the CID spectrum of A) versus loss of $\mathrm{CH}_{2} \mathrm{O}$ (not observed in the CID spectrum of A) in the keto isomer 1a.

$\mathrm{C}_{5} \mathrm{H}_{8} \mathrm{O}_{3}$ loss proceeds as follows: isomers $\mathbf{1 a}$ and $\mathbf{1 b}$ are connected by a conformational change of a single-bond rotation and can be presumed to have a small barrier (Fig. 3, pathway a, red). Fragmentation is triggered by $\mathrm{N}-\mathrm{C}$ bond cleavage (1) $\left.\mathbf{1}-\mathbf{1} \mathbf{c}^{\ddagger}\right)$ to give a complex of the nucleobase-sugar fragments $(\mathbf{1 c})$. This is followed by hydrogen-atom abstraction from the dissociated sugar moiety with concerted ring closure $\left(\mathbf{1} \mathbf{c}-\mathbf{1 d}^{\ddagger}\right)$ to yield the cyclised sugar $(\mathbf{1 d}, \mathbf{1 e})$. In contrast, loss of $\mathrm{CH}_{2} \mathrm{O}$ is triggered by hydrogen-atom abstraction from the $5^{\prime} \mathrm{OH}$ to the $\mathrm{N} 3$ position (Fig. 3, pathway b, blue). $\uparrow$ The free energy barrier for $\mathrm{C}_{5} \mathrm{H}_{8} \mathrm{O}_{3}$ loss is $108 \mathrm{~kJ} \mathrm{~mol}^{-1}$, which is slightly less than the barrier for loss of $\mathrm{CH}_{2} \mathrm{O}\left(110 \mathrm{~kJ} \mathrm{~mol}^{-1}\right)$, consistent with $\mathrm{C}_{5} \mathrm{H}_{8} \mathrm{O}_{3}$ loss being the main fragmentation channel. $\|$

T The same mechanism has been proposed for the loss of $\mathrm{CH}_{2} \mathrm{O}$ from deoxyadenosine analogs. ${ }^{41}$

\|| The barrier to keto-enol tautomerisation via an intramolecular 1,3 -shift is calculated to be $162 \mathrm{~kJ} \mathrm{~mol}^{-1}$ (via the transition structure shown in Fig. S6, ESI $\dagger$ ), and thus isomerisation of the keto to the enol form is unlikely to occur under the low-energy CID conditions used in our experiments.

\section{Conclusions}

The gas-phase structure and reactivity of $\mathrm{dG}^{{ }^{+}}$species $\mathbf{A}$ has been investigated by a combination of IR spectroscopy, mass spectrometry experiments involving both ion-molecule reactions and CID, and computational quantum chemistry calculations. This powerful combination has allowed us to assign $\mathbf{A}$ as the ground-state keto form. It undergoes a number of reactions with amines, including hydrogen-atom abstraction, proton transfer, electron transfer and adduct formation. Thus, the PA of $(\mathrm{dG}-\mathrm{H})^{\circ}$ radical has been experimentally bracketed as $994.3 \mathrm{~kJ} \mathrm{~mol}^{-1}>\mathrm{PA}$ $(\mathrm{dG}-\mathrm{H})^{\bullet}>981.8 \mathrm{~kJ} \mathrm{~mol}^{-1}$, consistent with our calculated value of $993.5 \mathrm{~kJ} \mathrm{~mol}^{-1}$ for removal of the $\mathrm{N} 1$ proton from the keto form of $\mathrm{dG}^{\bullet+}$. Similarly, the electron affinity of the $\mathrm{dG}^{\circ+}$ radical cation (A) has been bracketed as $756 \mathrm{~kJ} \mathrm{~mol}^{-1}>$ electron affinity $\mathbf{A}$ $>705 \mathrm{~kJ} \mathrm{~mol}^{-1}$, consistent with our calculated value of $712 \mathrm{~kJ} \mathrm{~mol}^{-1}$. Theoretical calculations on the unimolecular dissociation of the keto form (1a) of $\mathrm{dG}^{\bullet+}$ suggest that the favoured pathway involves cleavage of the glycosidic bond.

On a final note, the $\mathrm{dG}^{\bullet+}$ species $\mathbf{B}$ and $\mathbf{C}$ remain to be fully characterised.§ A technical challenge is that they need to be formed in a series of multistage mass spectrometry experiments. Nonetheless, preliminary results suggest that $\mathbf{B}$ and $\mathbf{C}$ consist of isomer(s) that are different to $\mathbf{A}$, and that they are less reactive than $\mathbf{A}$ in ion-molecule reactions.

\section{Acknowledgements}

Funding from the ARC (CoE program for RAJO and LR, APD for LF (CE0561607), ARF for GNK, and APF for LR), generous grants of computer time (to LR) from NCI NF and Intersect Australia Ltd, and (to RAJO) from VPAC, UPSud for a visiting Scholar Fellowship (to GNK). Financial support from the National FT-ICR network (FR 3624 CNRS) for conducting the research is gratefully acknowledged. 


\section{Notes and references}

1 A. C. Upton, Historical perspectives on radiation carcinogenesis, in Radiation Carcinogenesis, ed. A. C. Upton, R. E. Albert, F. J. Burns and R. E. Shore, Elsevier, New York, 1986, pp. 1-10.

2 (a) A. H. Sparrow and F. M. Rosenfeld, Science, 1946, 104, 245;

(b) G. Scholes, G. Stein and J. Weiss, Nature, 1949, 164, 709;

(c) G. Scholes, G. Stein and J. Weiss, Nature, 1950, 166, 640;

(d) B. E. Conway, L. Gilbert and J. A. V. Butler, J. Chem. Soc., 1950, 3421.

3 J. D. Watson and F. H. C. Crick, Nature, 1953, 171, 737.

4 C. von Sonntag, The Chemical Basis of Radiation Biology, Taylor and Francis, London, 1987.

5 (a) C. Chatgilialoglu and P. O'Neil, Exp. Gerontol., 2001, 36, 1459; (b) C. G. Fraga, M. K. Shigenaga, J.-W. Park, P. Degan and B. N. Ames, Proc. Natl. Acad. Sci. U. S. A., 1990, 87, 4533.

6 (a) A. O. Colson and M. D. Sevilla, Int. J. Radiat. Biol., 1995, 67, 627; (b) A. Kumar and M. D. Sevilla, Chem. Rev., 2010, 110, 7002; (c) S. Steenken, Chem. Rev., 1989, 89, 503; (d) C. J. Burrows and J. G. Muller, Chem. Rev., 1999, 98, 1109.

7 (a) L. P. Candeias and S. Steenken, J. Am. Chem. Soc., 1989, 111, 1094; (b) S. Steenken and S. V. Jovanovic, J. Am. Chem. Soc., 1997, 119, 617.

8 D. Khanduri, S. Collins, A. Kumar, A. Adhikary and M. D. Sevilla, J. Phys. Chem. B, 2008, 112, 2168.

9 T. Melvin, S. W. Botchway, A. W. Parker and P. O. O’Neill, J. Am. Chem. Soc., 1996, 118, 10031.

10 L. Mac Aleese and P. Maitre, Mass Spectrom. Rev., 2007, 26, 583 .

11 D. Oepts, A. F. G. Van der Meer and P. W. Van Amersfoort, Infrared Phys. Technol., 1995, 36, 297.

12 R. Prazeres, F. Glotin, C. Insa, D. A. Jaroszynski and J. M. Ortega, Eur. Phys. J. D, 1998, 3, 87.

13 J. Y. Salpin, S. Guillaumont, J. Tortajada, L. MacAleese, J. Lemaire and P. Maître, ChemPhysChem, 2007, 8, 2235.

14 (a) S. Osburn, J. D. Steill, J. Oomens, R. A. J. O'Hair, M. V. Stipdonk and V. Ryzhov, Chem. - Eur. J., 2011, 17, 873; (b) S. Osburn, G. Berden, J. Oomens, R. A. J. O'Hair and V. Ryzhov, J. Am. Soc. Mass Spectrom., 2011, 22, 1794; (c) S. Osburn, G. Berden, J. Oomens, R. A. J. O'Hair and V. Ryzhov, J. Am. Soc. Mass Spectrom., 2012, 23, 1019; (d) S. Osburn, T. Burgie, G. Berden, J. Oomens, R. A. J. O'Hair and V. Ryzhov, J. Phys. Chem. A, 2013, 117, 1144; (e) S. Osburn, G. Berden, J. Oomens, K. Gulyuz, N. C. Polfer, R. A. J. O'Hair and V. Ryzhov, ChemPlusChem, 2013, 78, 970.

15 L. Feketeová, G. N. Khairallah, B. Chan, V. Steinmetz, P. Maître, L. Radom and R. A. J. O'Hair, Chem. Commun., 2013, 49, 7343.

16 (a) P. Cheng and D. K. Bohme, J. Phys. Chem. B, 2007, 111, 11075; (b) L. Feketeová, E. Yuriev, J. D. Orbell, G. N. Khairallah and R. A. J. O'Hair, Int. J. Mass Spectrom., 2010, 304, 74; (c) S. Wee, R. A. J. O'Hair and W. D. McFadyen, Rapid Commun. Mass Spectrom., 2005, 19, 1797; (d) A. K. Y. Lam, B. F. Abrahams, M. J. Grannas, W. D. McFadyen and R. A. J. O'Hair, Dalton Trans., 2006, 5051.
17 H. Asami, S.-H. Urashima, M. Tsukamoto, A. Motoda, Y. Hayakawa and H. Saigusa, J. Phys. Chem. Lett., 2012, 3, 571.

18 J. M. Bakker, T. Besson, J. Lemaire, D. Scuderi and P. Maître, J. Phys. Chem. A, 2007, 111, 13415.

19 R. Malek, W. Metelmann-Strupat, M. Zeller and H. Muenster, Am. Biotechnol. Lab., 2005, 23, 8; S. Horning, R. Malek, A. Wieghaus and M. W. Senko, J. E. P. Syka, Proc. 51st ASMS Conf. Mass Spectrom. Allied Top., Montreal, Canada, 2003.

20 L. Feketeová, G. N. Khairallah and R. A. J. O’Hair, Eur. J. Mass Spectrom., 2008, 14, 107.

21 (a) W. A. Donald, C. J. McKenzie and R. A. J. O'Hair, Angew. Chem., Int. Ed., 2011, 50, 8379; (b) A. K. Y. Lam, C. Li, G. N. Khairallah, B. B. Kirk, S. J. Blanksby, A. J. Trevitt, U. Wille, R. A. J. O'Hair and G. da Silva, Phys. Chem. Chem. Phys., 2012, 14, 2417; (c) W. A. Donald, G. N. Khairallah and R. A. J. O'Hair, J. Am. Soc. Mass Spectrom., 2013, 24, 811.

22 M. J. Frisch, G. W. Trucks, H. B. Schlegel, G. E. Scuseria, M. A. Robb, J. R. Cheeseman, G. Scalmani, V. Barone, B. Mennucci, G. A. Petersson, H. Nakatsuji, M. Caricato, X. Li, H. P. Hratchian, A. F. Izmaylov, J. Bloino, G. Zheng, J. L. Sonnenberg, M. Hada, M. Ehara, K. Toyota, R. Fukuda, J. Hasegawa, M. Ishida, T. Nakajima, Y. Honda, O. Kitao, H. Nakai, T. Vreven, J. A. Montgomery Jr., J. E. Peralta, F. Ogliaro, M. Bearpark, J. J. Heyd, E. Brothers, K. N. Kudin, V. N. Staroverov, T. Keith, R. Kobayashi, J. Normand, K. Raghavachari, A. Rendell, J. C. Burant, S. S. Iyengar, J. Tomasi, M. Cossi, N. Rega, J. M. Millam, M. Klene, J. E. Knox, J. B. Cross, V. Bakken, C. Adamo, J. Jaramillo, R. Gomperts, R. E. Stratmann, O. Yazyev, A. J. Austin, R. Cammi, C. Pomelli, J. W. Ochterski, R. L. Martin, K. Morokuma, V. G. Zakrzewski, G. A. Voth, P. Salvador, J. J. Dannenberg, S. Dapprich, A. D. Daniels, O. Farkas, J. B. Foresman, J. V. Ortiz, J. Cioslowski and D. J. Fox, Gaussian 09, Revision C.01, Gaussian, Inc., Wallingford CT, 2010.

23 Y. Zhao and D. G. Truhlar, Theor. Chem. Acc., 2008, 120, 215. 24 J. P. Merrick, D. Moran and L. Radom, J. Phys. Chem. A, 2007, 111, 11683.

25 Y. Bouteiller, J. C. Gillet, G. Grégoire and J. P. Schermann, J. Phys. Chem. A, 2008, 112, 11656.

26 (a) A. Abo-riziq, B. O. Crews, I. Compagnon, J. Oomens, G. Meijer, G. Von Helden, M. Kabelac, P. Hobza and M. S. de Vries, J. Phys. Chem. A, 2007, 111, 7529; (b) E. Nir, I. Hünig, K. Kleinermanns and M. S. de Vries, ChemPhysChem, 2004, 5, 131; (c) H. Asami, S.-H. Urashima and H. Saigusa, Phys. Chem. Chem. Phys., 2009, 11, 10466.

27 (a) G. C. Y. Lee and S. I. Chan, J. Am. Chem. Soc., 1972, 94, 3218; (b) C. Chang, D. J. Ashworth, L. Chern, J. DaSilva Gomes, L. Jose, C. Lee, P. W. Mou and R. Narayan, Org. Magn. Reson., 1984, 22, 671.

28 (a) H. Fritzsche, D. Tresselt and C. Zimmer, Experientia, 1971, 27, 1253; (b) V. Andrushchenko and P. Bouř, J. Phys. Chem. B, 2009, 113, 283.

29 B. P. Pozniak and R. B. Cole, J. Am. Soc. Mass Spectrom., 2015, 27, 369 and references cited therein.

30 G. J. Van Berkel, S. A. McLuckey and G. L. Glish, Anal. Chem., 1992, 64, 1586. 
31 E. P. Hunter and S. G. Lias, J. Phys. Chem. Ref. Data, 1998, $27,413$.

32 D. K. Bohme, Int. J. Mass Spectrom., 1992, 115, 95-110.

33 (a) P. Mourgues, J. Chamot-Rooke, H. Nedev and H.-E. Audier, J. Mass Spectrom., 2001, 36, 102; (b) M. A. Trikoupis, P. C. Burgers, P. J. A. Ruttink and J. K. Terlouw, Int. J. Mass Spectrom., 2001, 210/211, 489; (c) D. Schroeder, J. Loos, R. Thissen, O. Dutuit, P. Mourgues, H.-E. Audier, C. Lifshitz and H. Schwarz, Angew. Chem., Int. Ed., 2002, 41, 2748; (d) M. A. Trikoupis, P. J. A. Ruttink, P. C. Burgers and J. K. Terlouw, Eur. J. Mass Spectrom., 2004, 10, 801.

34 F. Greco, A. Liguori, G. Sindona and N. Uccella, J. Am. Chem. Soc., 1990, 112, 9092.

35 A. Liguori, A. Napoli and G. Sindona, J. Am. Soc. Mass Spectrom., 2001, 12, 176.
36 C. E. Crespo-Hernandez, D. M. Close, L. Gorb and J. Leszczynski, J. Phys. Chem. B, 2007, 111, 5386.

37 NIST Chemistry WebBook, NIST Standard Reference Database Number 69, June 2005, ed. P. J. Linstrom and W. G. Mallard, National Institute of Standards and Technology, Gaithersburg, MD, 2005, http://webbook.nist.gov.au.

38 S. Kumari, C. L. Devi, S. Prabhakar, K. Bhanuprakash and M. Vairaman, J. Am. Soc. Mass Spectrom., 2010, 21, 136.

39 (a) K. Biemann and J. A. McCloskey, J. Am. Chem. Soc., 1962, 84, 2005; (b) NIST Standard Reference Database 69: NIST Chemistry WebBook.

40 L. Li and D. M. Lubman, Int. J. Mass Spectrom. Ion Processes, 1989, 88, 197.

41 S. J. Shaw, D. M. Desiderio, K. Tsuboyama and J. A. McCloskey, J. Am. Chem. Soc., 1970, 92, 2510. 